Research Article

\title{
Differential Expression of Glycolysis-Related Proteins in Follicular Neoplasms versus Hürthle Cell Neoplasms: A Retrospective Analysis
}

\author{
Hye Min Kim and Ja Seung Koo \\ Department of Pathology, Yonsei University College of Medicine, Seoul, Republic of Korea \\ Correspondence should be addressed to Ja Seung Koo; kjs1976@yuhs.ac
}

Received 27 March 2017; Accepted 15 June 2017; Published 16 July 2017

Academic Editor: Stamatios E. Theocharis

Copyright (c) 2017 Hye Min Kim and Ja Seung Koo. This is an open access article distributed under the Creative Commons Attribution License, which permits unrestricted use, distribution, and reproduction in any medium, provided the original work is properly cited.

\begin{abstract}
Purpose. Although currently classified as variants of follicular neoplasms (FNs), Hürthle cell neoplasms (HCNs) exhibit distinct biological characteristics. Hence, the metabolism of both neoplasms may also be different. The aims of this study were to investigate and compare the expression of glycolysis-related proteins in HCNs and FNs and to determine the clinical implications of such expression. Methods. Tissue microarrays were constructed with 265 samples of FNs (112 follicular carcinomas (FCs) and 153 follicular adenomas (FAs)) as well as 108 samples of HCNs (27 Hürthle cell carcinomas (HCCs) and 81 Hürthle cell adenomas (HCAs)). Immunohistochemical staining for the glycolysis-related molecules Glut-1, hexokinase II, CAIX, and MCT4 was performed. Results. The expression levels of Glut-1, hexokinase II, CAIX, and MCT4 were significantly higher in HCNs than in FNs $(p<0.001)$. Glut-1, hexokinase II, CAIX, and MCT4 expression levels were highest in HCC, followed by HCA, FC, and FA (all $p<0.001$ ). In HCC, hexokinase II positivity was associated with large tumor size $(>4 \mathrm{~cm})(p=0.046)$, CAIX positivity with vascular invasion $(p=0.005)$, and MCT4 positivity with extrathyroidal extension $(p=0.030)$. Conclusion. The expression levels of the glycolysis-related proteins Glut-1, hexokinase II, CAIX, and MCT4 were higher in HCNs than in FNs and in HCCs than in HCAs.
\end{abstract}

\section{Introduction}

The metabolism of malignant tumors is characterized by the Warburg effect, in which a metabolic shift from oxidative phosphorylation in the mitochondria towards glycolysis occurs in tumor cells [1]. Key molecules involved in regulating glycolysis and its products include Glut-1, hexokinase II, CAIX, and MCT4. Glut-1 is a glucose transporter [2] while hexokinase II is the initiating enzyme in glycolysis that phosphorylates glucose to produce glucose-6-phosphate [3]. CAIX leads to the reversible hydration of carbon dioxide to neutralize the acidification caused by lactate formed during glycolysis [4], and the MCT4 channel exports lactate produced by glycolysis out of the cell [5].

Currently, the World Health Organization classifies Hürthle cell neoplasm $(\mathrm{HCN})$ as an oncocytic variant of follicular neoplasm (FN) [6]. Hürthle cells are considered an oxyphilic variant of follicular epithelial cells and are characterized by large-sized cells with polygonal to square shapes, distinct borders, hyperchromatic nuclei with prominent nucleoli, and abundant eosinophilic granular cytoplasm owing to the accumulation of large numbers of intracytoplasmic mitochondria. Hürthle cell adenomas (HCAs) account for $10-15 \%$ of follicular adenomas (FAs), while Hürthle cell carcinomas (HCCs) comprise $20-25 \%$ of follicular carcinomas (FCs) [7]; however, several studies have suggested that $\mathrm{HCN}$ could be a distinct disease. The rate of malignancy in FNs ranges from $15 \%$ to $30 \%$, compared to a higher rate of $25-45 \%$ in HCNs [8-12]. Compared to FC, HCC is prone to metastasize to the lymph nodes, soft tissues of the neck, [13], and distant sites [14] and exhibits a higher rate of resistance to iodine therapy. Therefore, the prognosis of HCC is poor; this disease carries a higher rate of recurrence and mortality [14-17]. Furthermore, genomic analysis of HCCs 
TABLe 1: Source, clone, and dilution of antibodies used in this study.

\begin{tabular}{lccc}
\hline Antibody & Clone & Dilution & Company \\
\hline Glut-1 & SPM498 & $1: 200$ & Abcam, Cambridge, UK \\
Hexokinase II & 3D3 & $1: 200$ & Abcam, Cambridge, UK \\
CAIX & Polyclonal & $1: 100$ & Abcam, Cambridge, UK \\
MCT4 & Polyclonal & $1: 100$ & Santa Cruz, CA, USA \\
Ki-67 & MIB-1 & $1: 150$ & Dako, Denmark AS, Glostrup, Denmark \\
\hline
\end{tabular}

suggests that it may represent a unique class of thyroid malignancies [18], and molecular studies revealed that the TERT C228T promoter mutation is common in HCNs [19].

While HCN and FN tumors exhibit different biological characteristics, a previous study using $\left[{ }^{18} \mathrm{~F}\right]$-2-fluoro-2deoxy-D-glucose $\left({ }^{18} \mathrm{~F}-\mathrm{FDG}\right)$ positron emission tomography (PET) also showed that HCAs exhibit higher focal ${ }^{18} \mathrm{~F}$-FDG uptakes and maximum standardized update values (SUVmax) than FAs [20]. Therefore, it could be speculated that the metabolic features of HCN and FN differ; however, this has not been researched extensively to date. In a previous study, we have demonstrated differential expression of glycolysis-related protein among different types of thyroid cancer [21]. Therefore, the aims of this study were to investigate the expression of glycolysis-related proteins in HCN and FN and to examine the clinical implications of any differences in expression levels.

\section{Materials and Methods}

2.1. Patient Selection. Patients who were diagnosed with FN and HCN after surgery at the Severance Hospital between January 2000 and December 2013 and with available paraffin blocks and slides for histologic evaluation were included in this study. All cases were retrospectively reviewed by a thyroid pathologist (JSK), and histological evaluation was performed after hematoxylin and eosin staining. Clinicopathologic data were obtained from the patients' medical records and included age at diagnosis, disease recurrence, metastasis, current status, and duration of follow-up. The tumor size, location (right or left lobe), extent (confined to the thyroid parenchyma or with extrathyroidal spread), and number of metastatic lymph nodes were also noted after reviewing the slides and surgical pathology reports. This study was approved by the Institutional Review Board of Yonsei University Severance Hospital.

2.2. Tissue Microarray. Representative areas were selected on hematoxylin and eosin-stained slides, and a corresponding spot was marked on the surface of the matching paraffin block. Three-millimeter-sized tissue cores were extracted by using a manual tissue arrayer from the selected areas and placed into a $6 \times 5$ recipient block. More than two tissue cores were extracted from each sample to minimize extraction bias. Each tissue core was assigned a unique tissue microarray location number that was linked to a database containing other clinicopathologic data.
2.3. Immunohistochemistry. Antibodies used for immunohistochemistry are listed in Table 1. All immunohistochemistry was performed with formalin-fixed, paraffin-embedded tissue sections using an automatic immunohistochemistry staining device (Benchmark XT, Ventana Medical System, Tucson, AZ, USA). Briefly, $5 \mu$ m-thick formaldehyde-fixed paraffin-embedded tissue sections were transferred onto adhesive slides and dried at $62^{\circ} \mathrm{C}$ for 30 minutes. Standard heat epitope retrieval was performed for 30 minutes in ethylene diamine tetraacetic acid, $\mathrm{pH} 8.0$, in the autostainer. The samples were then incubated with primary antibodies. Afterwards, the sections were incubated with biotinylated anti-mouse immunoglobulins, peroxidase-labeled streptavidin (LSAB Kit, DakoCytomation), and 3,30-diaminobenzidine. Negative control samples were processed without the primary antibody. Positive control tissues were used as per the manufacturer's recommendation. Slides were counterstained with Harris hematoxylin. Optimal primary antibody incubation times and concentrations were determined by serial dilutions of each immunohistochemical assay using a tissue block fixed and embedded exactly as performed for the samples.

2.4. Interpretation of Immunohistochemical Staining. Immunohistochemical markers were accessed by light microscopy. The stained slides were semiquantitatively evaluated as previously described [22]. Tumor cell staining was assessed as 0 : negative or weak immunostaining in $<1 \%$ of the tumor cells, 1: focal expression in $1-10 \%$ of tumor cells, 2 : positive in $11-50 \%$ of tumor cells, and 3: positive in $51-100 \%$ of tumor cells. These evaluations were applied over the entire area of the tumor, which was scored as follows; 0-1: negative, 2: low-positive, and 3: high-positive. For the Ki-67 labeling index (Ki-67 L.I.), grading was performed as previously described, with some modifications $[23,24]$. Tumor cells with $\mathrm{Ki}-67$ L.I. $<3 \%$ was graded as $0,3 \% \leq \mathrm{Ki}-67$ L.I. $\leq 5 \%$ as 1 , and $5 \%<\mathrm{Ki}-67$ L.I. as 2. "Glycolysis type" samples were defined as those positive for two or more of the markers Glut-1, hexokinase II, CAIX, and MCT4; otherwise, the sample was defined as nonglycolysis type.

2.5. Statistical Analysis. Data were analyzed using IBM SPSS Statistics for Windows, Version 21.0 (IBM Corp. Released 2012, Armonk, NY, USA). For determination of statistical significance, the Student's $t$-test and Fisher's exact test were used for continuous and categorical variables, respectively. For analyzing data with multiple comparisons, a corrected $p$ value with the application of the Bonferroni multiple comparison procedure was used. Correlation among glycolysis- 
TABLE 2: Expression of glycolysis-related proteins in follicular neoplasms and Hürthle cell neoplasms.

\begin{tabular}{|c|c|c|c|c|}
\hline Parameters & Total $N=373(\%)$ & Follicular neoplasm $n=265(\%)$ & Hürthle cell neoplasm $n=108(\%)$ & $p$ value \\
\hline GLUT-1 & & & & $<0.001$ \\
\hline Negative & $349(93.6)$ & $263(99.2)$ & $86(79.6)$ & \\
\hline Positive & $24(6.4)$ & $2(0.8)$ & $22(20.4)$ & \\
\hline Hexokinase II & & & & $<0.001$ \\
\hline Negative & $289(77.5)$ & $229(86.4)$ & $60(55.6)$ & \\
\hline Positive & $84(22.5)$ & $36(13.6)$ & $48(44.4)$ & \\
\hline CAIX & & & & $<0.001$ \\
\hline Negative & $348(93.3)$ & $263(99.2)$ & $85(78.7)$ & \\
\hline Positive & $25(6.7)$ & $2(0.8)$ & $23(21.3)$ & \\
\hline MCT4 & & & & $<0.001$ \\
\hline Negative & $279(74.8)$ & $215(81.1)$ & $64(59.3)$ & \\
\hline Positive & $94(25.2)$ & $50(18.9)$ & $44(40.7)$ & \\
\hline
\end{tabular}

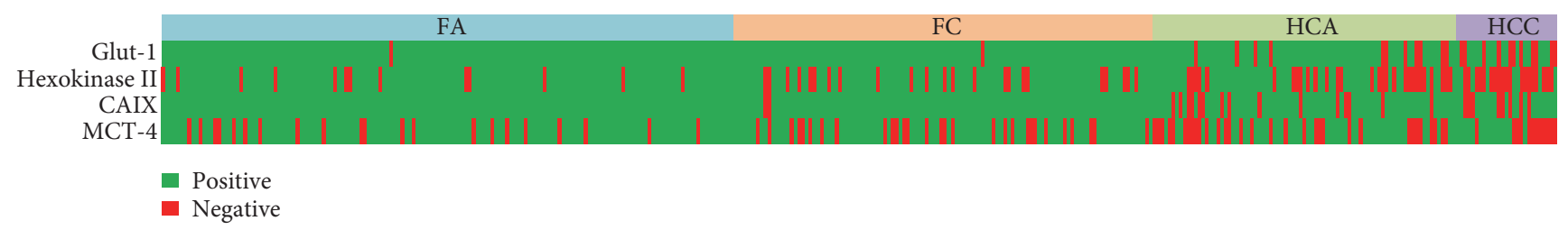

FIGURE 1: Heat map of glycolysis-related proteins found in follicular neoplasms and Hürthle cell neoplasms. (FA: follicular adenoma; FC: follicular carcinoma; HCA: Hürthle cell adenoma; HCC: Hürthle cell carcinoma).

related proteins, clinicopathologic factors, and Ki-67 L.I. was compared using the Spearman's rho. Statistical significance was set to $p<0.05$. Cox proportional hazards model with univariate and multivariate analyses was used to evaluate the prognostic factors for disease-free and overall survival.

\section{Results}

3.1. Basal Characteristic of Follicular Neoplasms and Hürthle Cell Neoplasms. This study included 265 patients with FN: 153 with FA and 112 with FC. Of the 112 FCs, 99 cases were of the minimally invasive type and 13 were widely invasive. Clinicopathologic features of the FCs are presented in Supplementary Table 1 available online at https://doi.org/10.1155/2017/6230294. Additionally, 108 patients with HCN were included, 81 with $\mathrm{HCA}$ and 27 with HCC. The clinicopathologic features of $\mathrm{HCN}$ are presented in Supplementary Table 1.

3.2. Expression of Glycolysis-Related Proteins in Follicular Neoplasms and Hürthle Cell Neoplasms. The expression of Glut-1, hexokinase II, CAIX, and MCT4 was significantly higher in HCNs than in FNs $(p<0.001$, Table 2 and Figure 1). When comparing the expression of glycolysisrelated proteins between FA, FC, HCA, and HCC, Glut-1, hexokinase II, CAIX, and MCT4 expression was highest in HCC, followed by HCA, FC, and FA (all $p<0.001$, Table 3 and Figure 2). Furthermore, the number of positive markers among the four glycolysis-related markers was examined in FA, FC, HCA, and HCC. The percentage of cases with the number of positive markers was the highest in HCC, followed by HCA, FC, and FA (Table 4 and Figure 3). The ratio of glycolysis type was the highest in HCC, followed by HCA, FC, and FA (Figure 4).

3.3. Correlation between the Expression of Glycolysis-Related Proteins and Clinicopathologic Factors in Hürthle Cell Carcinoma. We investigated the correlation between the expression of glycolysis-related proteins and clinicopathologic factors in HCC. Hexokinase II positivity was associated with large tumor size $(>4 \mathrm{~cm})(r=0.384, p=0.046)$, CAIX positivity with vascular invasion $(r=0.545, p=0.005)$, and MCT4 positivity with extrathyroidal extension $(r=0.418$, $p=0.030$ ) (Figure 5).

3.4. Correlation between the Expression of Glycolysis-Related Proteins and Ki-67 Labeling Index in Follicular Carcinoma and Hürthle Cell Carcinoma. Next, we evaluated the correlation between Ki-67 L.I. and the expression of glycolysisrelated proteins in FC and HCC. Correlation analysis showed that Ki-67 L.I. was related to MCT4 in FC $(r=0.187$, $p=0.048)$ and GLUT1 expression $(r=0.419, p=0.029)$ in HCC (Table 5).

3.5. The Impact of the Expression of Glycolysis-Related Proteins on Prognosis. Finally, we investigated the impact of the clinical parameters and the expression of glycolysisrelated proteins in the clinical outcomes of patients with FC and HCC. During the follow-up period, 11 patients experience disease recurrence, while 5 patients had suffered death. 
TABLE 3: Expression of glycolysis-related proteins in follicular neoplasms and Hürthle cell neoplasms.

\begin{tabular}{|c|c|c|c|c|c|}
\hline \multirow{2}{*}{ Parameters } & \multicolumn{2}{|c|}{ Follicular neoplasm $n=265(\%)$} & \multicolumn{2}{|c|}{ Hürthle cell neoplasm $n=108(\%)$} & \multirow{2}{*}{$p$ value } \\
\hline & FA $n=153(\%)$ & $\mathrm{FC} n=112(\%)$ & HCA $n=81(\%)$ & $\operatorname{HCC} n=27(\%)$ & \\
\hline GLUT-1 & & & & & $<0.001$ \\
\hline Negative & $152(99.3)$ & $111(99.1)$ & $70(86.4)$ & $16(59.3)$ & \\
\hline Positive & $1(0.7)$ & $1(0.9)$ & $11(13.6)$ & $11(40.7)$ & \\
\hline Hexokinase II & & & & & $<0.001$ \\
\hline Negative & $140(91.5)$ & $89(79.5)$ & $52(64.2)$ & $8(29.6)$ & \\
\hline Positive & $13(8.5)$ & $23(20.5)$ & $29(35.8)$ & $19(70.4)$ & \\
\hline CAIX & & & & & $<0.001$ \\
\hline Negative & $153(100.0)$ & $110(98.2)$ & $66(81.5)$ & $19(70.4)$ & \\
\hline Positive & $0(0.0)$ & $2(1.8)$ & $15(18.5)$ & $8(29.6)$ & \\
\hline MCT4 (T) & & & & & $<0.001$ \\
\hline Negative & $132(86.3)$ & $83(74.1)$ & $49(60.5)$ & $15(55.6)$ & \\
\hline Positive & $21(13.7)$ & $29(25.9)$ & $32(39.5)$ & $12(44.4)$ & \\
\hline
\end{tabular}

FA: follicular adenoma; FC: follicular carcinoma; HCA: Hürthle cell adenoma; HCC: Hürthle cell carcinoma.
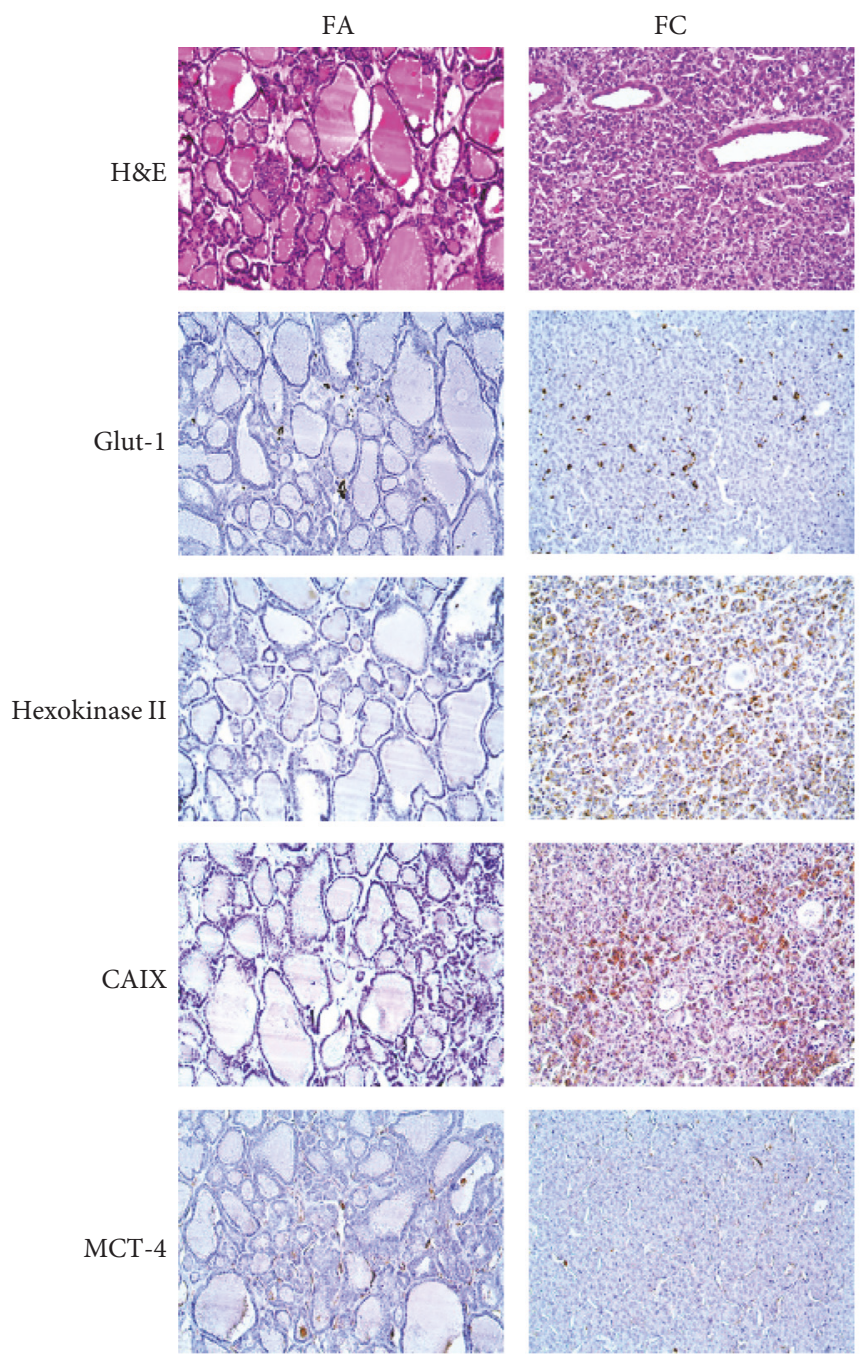
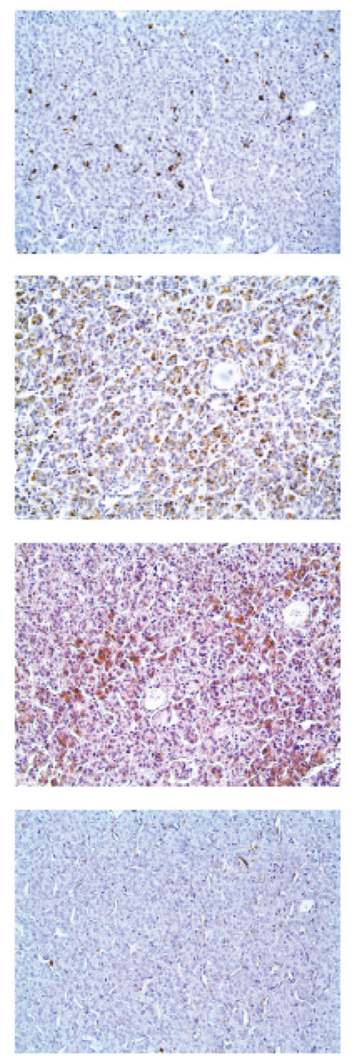
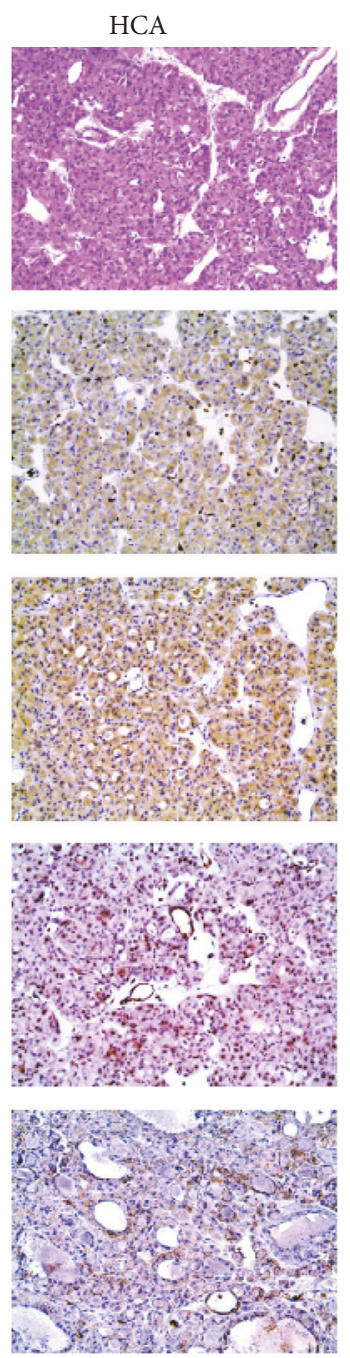
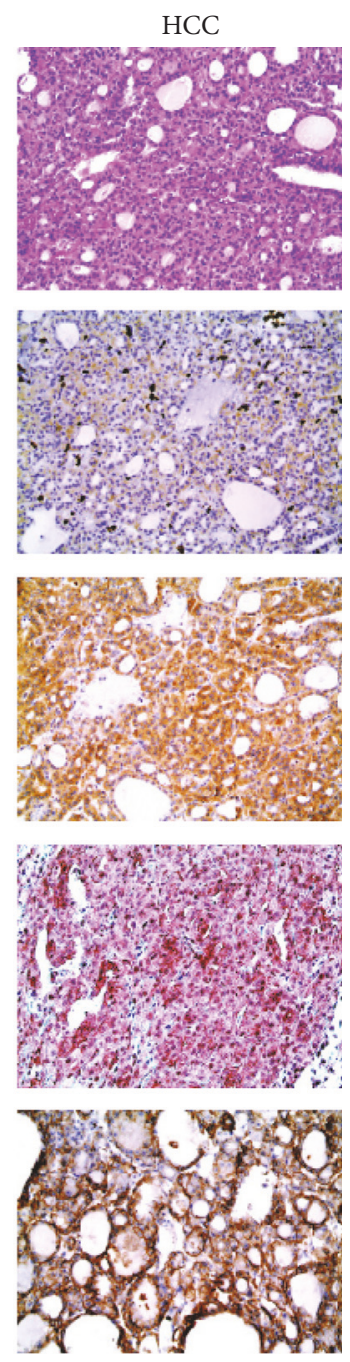

FIGURE 2: Expression of glycolysis-related proteins in follicular neoplasms and Hürthle cell neoplasms. The expression of Glut-1, hexokinase II, CAIX, and MCT4 was significantly higher in Hürthle cell neoplasms compared to follicular neoplasms and in Hürthle cell carcinomas than in Hürthle cell adenomas. (FA: follicular adenoma; FC: follicular carcinoma; HCA: Hürthle cell adenoma; HCC: Hürthle cell carcinoma). 
TABLE 4: Number of positive markers for glycolysis in follicular neoplasms and Hürthle cell neoplasms.

\begin{tabular}{|c|c|c|c|c|c|c|}
\hline Parameter & Total $N=373(\%)$ & FA $n=153(\%)$ & $\mathrm{FC} n=112(\%)$ & HCA $n=84(\%)$ & HCC $n=27(\%)$ & $p$ value \\
\hline $\begin{array}{l}\text { Number of positive } \\
\text { markers for glycolysis }\end{array}$ & & & & & & $<0.001$ \\
\hline 0 & $215(57.6)$ & $120(78.4)$ & $67(59.8)$ & $26(32.1)$ & $2(7.4)$ & \\
\hline 1 & $111(29.8)$ & $33(21.6)$ & $36(32.1)$ & $33(40.7)$ & $9(33.3)$ & \\
\hline 2 & $28(7.5)$ & $0(0.0)$ & $8(7.1)$ & $12(14.8)$ & $8(29.6)$ & \\
\hline 3 & $18(4.8)$ & $0(0.0)$ & $1(0.9)$ & $10(12.3)$ & $7(25.9)$ & \\
\hline 4 & $1(0.3)$ & $0(0.0)$ & $0(0.0)$ & $0(0.0)$ & $1(3.7)$ & \\
\hline
\end{tabular}

FA: follicular adenoma; FC: follicular carcinoma; HCA: Hürthle cell adenoma; HCC: Hürthle cell carcinoma.

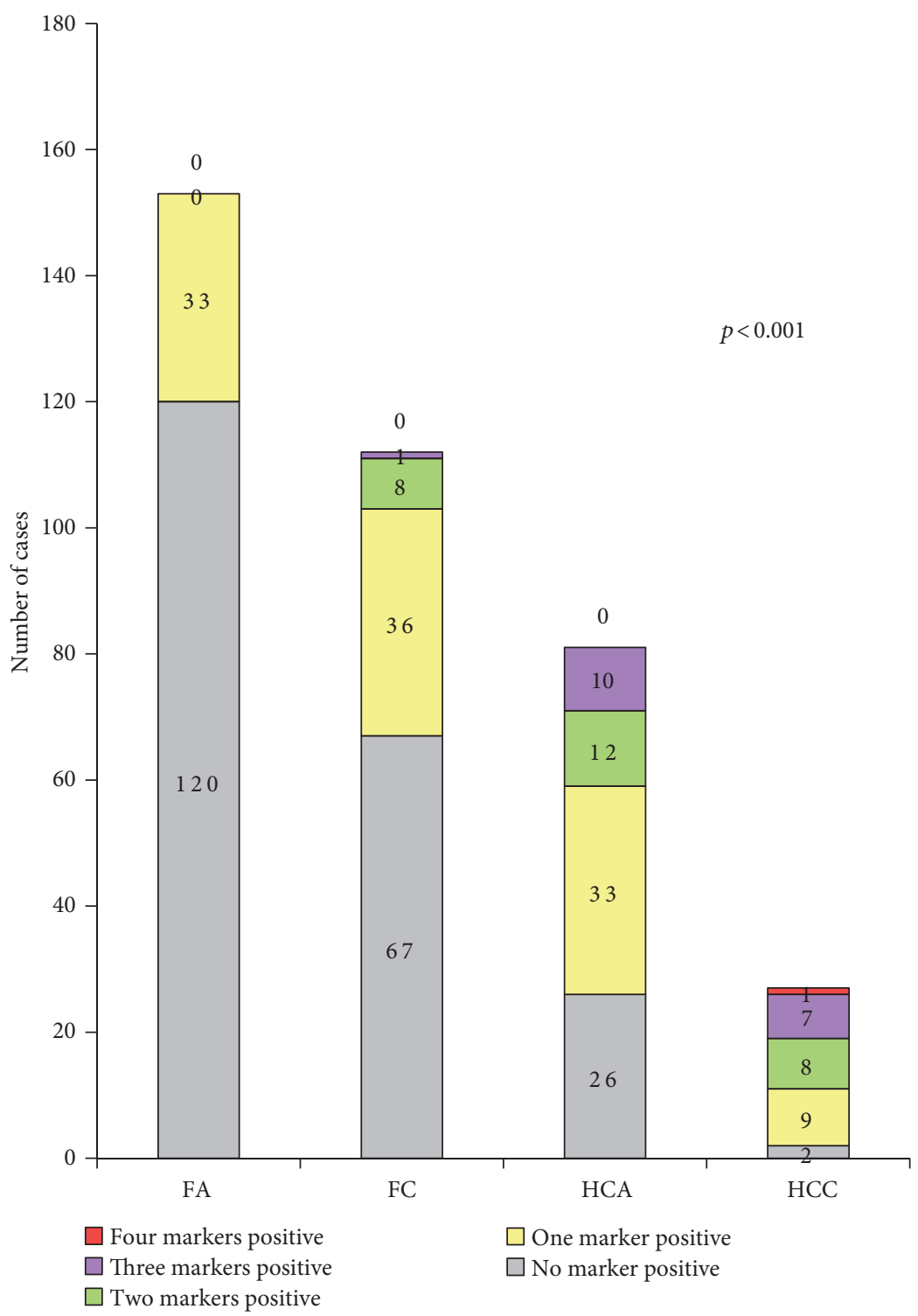

FIGURE 3: Number of positive glycolytic markers in follicular neoplasms and Hürthle cell neoplasms. (FA: follicular adenoma; FC: follicular carcinoma; HCA: Hürthle cell adenoma; HCC: Hürthle cell carcinoma).

In multivariate analysis, female sex (OR 0.201, 95\% CI $0.061-0.060, p=0.008$ ) and extrathyroidal extension (OR $4.937,95 \%$ CI $1.503-16.208, p=0.008)$ was related to disease-free survival (Table 6), while only lymph node metastasis (OR 15.742, 95\% CI 1.723-143.770, $p=0.014$ ) was related to overall survival (Table 7). However, the 


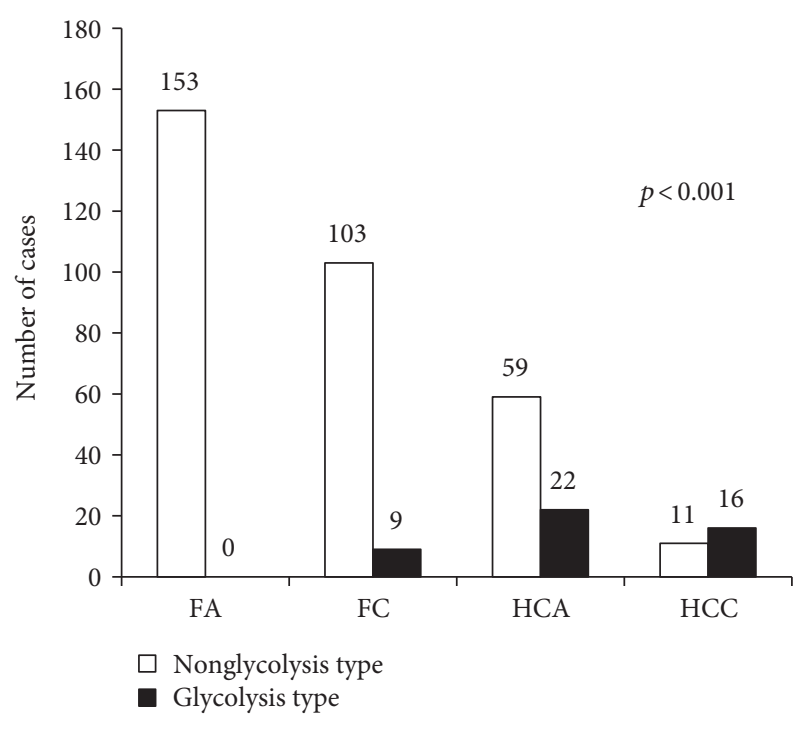

FIGURE 4: Glycolysis type in follicular neoplasms and Hürthle cell neoplasms. (FA: follicular adenoma; FC: follicular carcinoma; HCA: Hürthle cell adenoma; HCC: Hürthle cell carcinoma).

expression of glycolysis-related proteins Glut-1, hexokinase II, CAIX, and MCT4 levels was not significantly related to disease-free and overall survival (Tables 6 and 7).

\section{Discussion}

We found that the expression levels of the glycolysisrelated proteins Glut-1, hexokinase II, CAIX, and MCT4 were significantly higher in HCNs than in FNs. FDG is a glucose analog, and ${ }^{18} \mathrm{~F}-\mathrm{FDG}$ is the most commonly used radiotracer in PET/computed tomography image acquisition. As glucose metabolism is increased in glycolytic tissues, such as those with malignancies, such tissues increase their uptake of ${ }^{18} \mathrm{~F}-\mathrm{FDG}$. Our findings are consistent with those of a previous study showing that HCAs exhibit a higher focal FDG uptake and higher SUVmax compared to FA, suggesting that glycolysis is more active in HCAs $[20,25]$.

There is ample evidence of the differential expression of glycolysis-related proteins in tumors. In a genomic dissection study, the PI3K-AkT-mTOR and Wnt/ $\beta$-catenin pathways were shown to be activated in HCC, which exhibited a different molecular profile than FN [18]. The PI3K-Akt pathway plays a pivotal role in translocating Glut-1 from the cytoplasm to the plasma membrane in cells of endocrine organs such as the thyroid gland [26] and pancreas [27]. Furthermore, hexokinase II was shown to play a critical role in the proliferation of hepatocellular carcinoma cells in an Akt signaling pathway-dependent manner [28]. Lee et al. demonstrated that Wnt signaling activation in breast cancer cells promotes glycolysis, which is indirectly mediated by Snail, the transcriptional repressor of cytochrome c oxidase [29]. Therefore, it makes sense that the levels of glycolysis-related proteins are increased in HCC, since PI3K-AkT-mTOR and $\mathrm{Wnt} / \beta$-catenin pathways are activated in these tumors. Additionally, all HCNs express the hTERT protein [30] and TERT C228T promoter mutation is common in HCNs [19]. HCCs also exhibit markedly shortened telomeres $[19,30]$. In previous studies, several genes involved in the glycolytic pathway were shown to be downregulated following TERT knockdown, suggesting that TERT directly regulates cancer cell metabolism, especially glycolysis $[31,32]$. These findings suggest that the higher expression of glycolysis-related proteins in HCNs is associated with TERT activity; however, additional studies are required to clarify this.

Glycolytic marker positivity was the highest in HCCs, followed by HCAs, FCs, and FAs. The proportions of "glycolysis type" samples followed the same pattern. The expression levels of glycolysis-related proteins were higher in carcinomas than in adenomas in both HCNs and FNs, suggesting that cancer cells utilize glycolysis for proliferation and cell growth. In a previous study, autophagy and senescence in cancer-associated fibroblasts were shown to contribute to tumor growth and metastasis via glycolysis and ketone production [33]. Furthermore, glycolysis triggered tumor metastasis by promoting resistance against anoikis, which is a barrier to tumor metastasis, in mammary epithelial cell lines [34], whereas inhibition of glycolysis in head and neck squamous cell carcinoma suppressed tumor growth and metastasis [35]. These findings are consistent with our results that showed that the expression of glycolysis-related proteins is higher in carcinomas than in adenomas; however, the underlying mechanisms of increased expression of glycolysis-related proteins in HCC require further investigation.

We have demonstrated that hexokinase II positivity was associated with large tumor size and CAIX positivity with vascular invasion, whereas MCT4 positivity was linked to extrathyroidal extension. Although there are no previous studies directly comparing glycolysis activities between FN and $\mathrm{HCN}$, a previous study did evaluate glycolysis-related protein expression in breast solid papillary carcinoma, with results similar to ours [36]. Separately, the efflux of hydrogen ions mediated by CAIX neutralizes the intracellular acidic microenvironment that can cause the degradation of the extracellular matrix and basement membrane [37]. Therefore, it can be speculated that higher expression of CAIX influences the invasive growth of tumor cells. Previously, stromal MCT4 expression was shown to reflect the oxidative stress experienced by cancer-associated fibroblasts [38]. Hence, it is possible that oxidative stress is increased in cancer-associated fibroblasts in the event of extrathyroidal extension following the aggressive growth of cancer cells, resulting in increased expression of MCT4. Likewise, Ki-67, proliferation marker that is expressed in tumor cells also correlated with MCT4 in FC. However, this hypothesis should be tested in future studies. In a previous study that evaluated glycolysis-related protein expression in colorectal carcinoma, tumor size was associated with hexokinase II positivity; this makes sense because the glycolysis pathway provides energy to cancer cells and serves as a biomoleculer precursor of proliferation [39]. Additionally, hexokinase II hampers cancer cell apoptosis and increases mitochondrial stability and cell proliferation activity via PI3K-dependent 

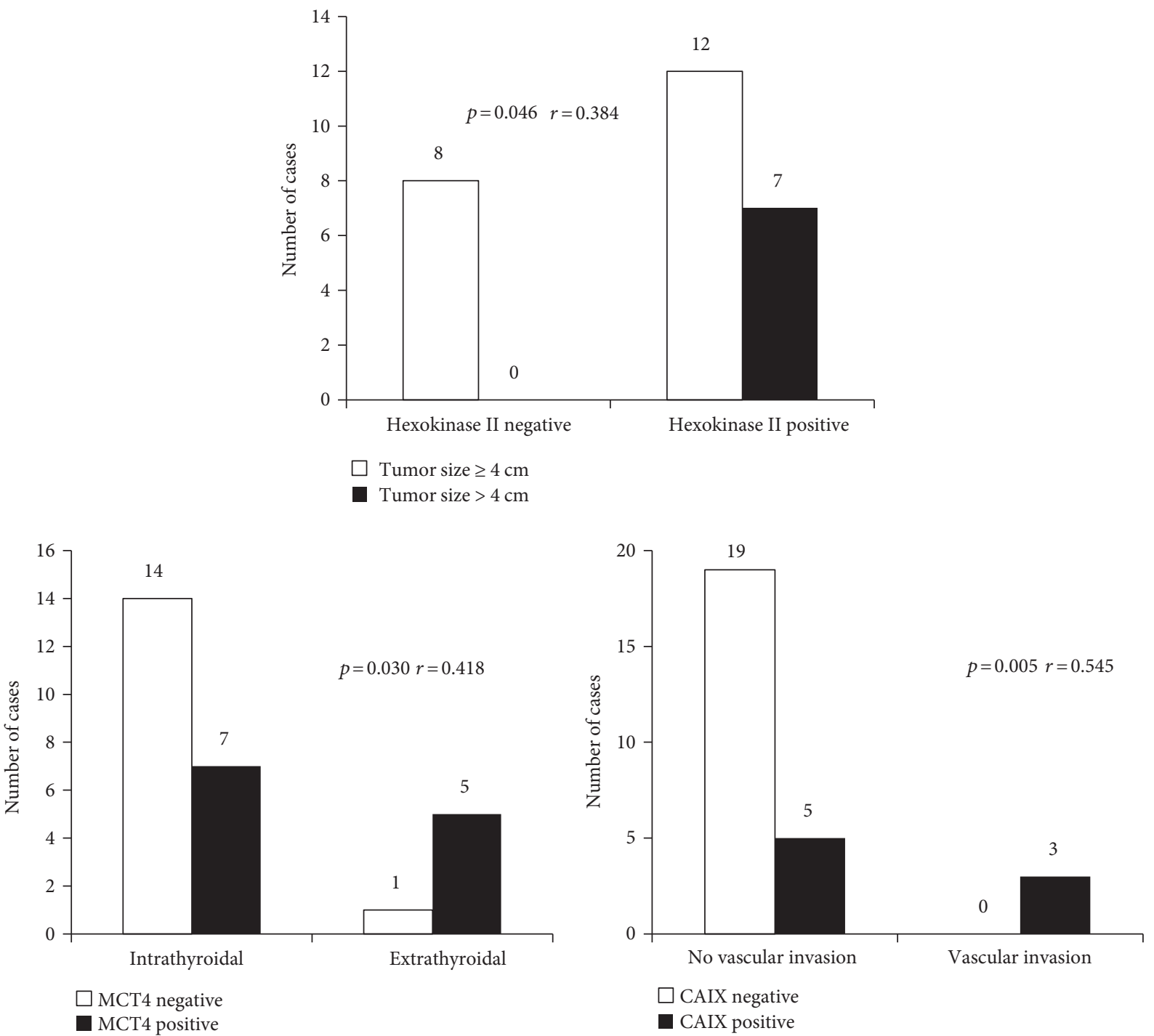

FIGURE 5: Correlation between the expression of glycolysis-related proteins and clinicopathologic factors in Hürthle cell carcinoma.

TABLE 5: Correlation between the expression of glycolysis-related proteins and Ki-67 labeling index in follicular carcinomas and Hürthle cell carcinomas.

\begin{tabular}{lccc}
\hline \multirow{2}{*}{ Parameter } & \multicolumn{2}{c}{ Follicular carcinoma $(n=112)$} & \multicolumn{2}{c}{ Hürthle cell carcinoma $(n=27)$} & Correlation coefficient \\
& Correlation coefficient & $p$ value & 0.419 \\
GLUT1 & -0.001 & 0.992 & 0.076 \\
Hexokinase II & 0.001 & 0.989 & 0.245 \\
CAIX & -0.059 & 0.531 & 0.79 \\
MCT4 & 0.187 & 0.048 & 0.277 \\
\hline
\end{tabular}

and PI3K-independent pathways in different types of carcinomas [28, 40-43]; these data are consistent with our results.

The clinical significance of this study is that glycolysisrelated proteins could be a potential therapeutic target in the treatment of HCC. As lymph node metastasis in HCC reportedly occurs in $5.3-13 \%$ of cases $[19,44-46]$, aggressive surgical treatment or complete thyroidectomy is necessary [47]. Several adjuvant therapy treatment options have been suggested following surgical resection, including thyroxine suppression, radioiodine, cervical radiation, directed therapy for distant metastasis, and systemic therapy [47]. However, the optimal treatment option is still unclear. In previous studies, the targeting of Glut-1 [27, 48-50], hexokinase II $[51,52]$, CAIX [53, 54], and MCT4 [55] suppressed tumor growth, invasion, and metastasis. Therefore, targeting glycolysis-related proteins in HCC might also be a promising 
TABLE 6: Cox-proportional hazard analysis for disease-free survival in follicular carcinomas and Hürthle cell carcinomas.

\begin{tabular}{|c|c|c|c|c|c|c|}
\hline \multirow{2}{*}{ Parameter } & \multicolumn{3}{|c|}{ Univariate analysis } & \multicolumn{3}{|c|}{ Multivariate analysis } \\
\hline & Odd ratio & $95 \% \mathrm{CI}$ & $p$ value & Odd ratio & $95 \% \mathrm{CI}$ & $p$ value \\
\hline Age $\geq 45$ (years) & 3.656 & $0.789-16.934$ & 0.097 & & & \\
\hline Female sex & 0.208 & $0.063-0.683$ & 0.009 & 0.201 & $0.061-0.660$ & 0.008 \\
\hline Tumor size $>2.0(\mathrm{~cm})$ & 5.363 & $0.686-41.910$ & 0.109 & & & \\
\hline Capsular invasion & 1.320 & $0.169-10.316$ & 0.790 & & & \\
\hline Vascular invasion & 3.204 & $0.938-10.946$ & 0.063 & & & \\
\hline Extrathyroidal extension & 4.753 & $1.447-15.612$ & 0.010 & 4.937 & $1.503-16.208$ & 0.008 \\
\hline Lymph node metastasis & $\mathrm{n} / \mathrm{a}$ & $\mathrm{n} / \mathrm{a}$ & $\mathrm{n} / \mathrm{a}$ & & & \\
\hline GLUT-1 positivity & $\mathrm{n} / \mathrm{a}$ & $\mathrm{n} / \mathrm{a}$ & $\mathrm{n} / \mathrm{a}$ & & & \\
\hline Hexokinase II positivity & 0.523 & $0.113-2.422$ & 0.407 & & & \\
\hline CAIX positivity & $\mathrm{n} / \mathrm{a}$ & $\mathrm{n} / \mathrm{a}$ & $\mathrm{n} / \mathrm{a}$ & & & \\
\hline MCT4 $(\mathrm{T})$ positivity & 0.264 & $0.033-2.066$ & 0.204 & & & \\
\hline Glycolysis type* $^{*}$ & $\mathrm{n} / \mathrm{a}$ & $\mathrm{n} / \mathrm{a}$ & $\mathrm{n} / \mathrm{a}$ & & & \\
\hline
\end{tabular}

n/a: not applicable. *Glycolysis type was defined as those positive for two or more of the glycolysis related proteins.

TABLE 7: Cox-proportional hazard analysis for overall survival in follicular carcinomas and Hürthle cell carcinomas.

\begin{tabular}{|c|c|c|c|c|c|c|}
\hline \multirow{2}{*}{ Parameter } & \multicolumn{3}{|c|}{ Univariate analysis } & \multicolumn{3}{|c|}{ Multivariate analysis } \\
\hline & Odd ratio & $95 \%$ CI & $p$ value & Odd ratio & $95 \%$ CI & $p$ value \\
\hline Age $\geq 45$ (years) & 0.017 & $0.001-23.502$ & 0.270 & & & \\
\hline Female sex & 0.326 & $0.053-1.994$ & 0.225 & & & \\
\hline Tumor size $>2.0(\mathrm{~cm})$ & 2.151 & $0.240-19.242$ & 0.493 & & & \\
\hline Capsular invasion & 0.546 & $0.060-4.899$ & 0.589 & & & \\
\hline Vascular invasion & 2.530 & $0.421-15.201$ & 0.310 & & & \\
\hline Extrathyroidal extension & 3.903 & $0.651-23.401$ & 0.136 & & & \\
\hline Lymph node metastasis & 15.742 & $1.723-143.770$ & 0.014 & 15.742 & $1.723-143.770$ & 0.014 \\
\hline GLUT-1 positivity & $\mathrm{n} / \mathrm{a}$ & $\mathrm{n} / \mathrm{a}$ & $\mathrm{n} / \mathrm{a}$ & & & \\
\hline Hexokinase II positivity & $\mathrm{n} / \mathrm{a}$ & $\mathrm{n} / \mathrm{a}$ & $\mathrm{n} / \mathrm{a}$ & & & \\
\hline CAIX positivity & $\mathrm{n} / \mathrm{a}$ & $\mathrm{n} / \mathrm{a}$ & $\mathrm{n} / \mathrm{a}$ & & & \\
\hline MCT4 (T) positivity & 0.790 & $0.087-7.225$ & 0.838 & & & \\
\hline Glycolysis type* & $\mathrm{n} / \mathrm{a}$ & $\mathrm{n} / \mathrm{a}$ & $\mathrm{n} / \mathrm{a}$ & & & \\
\hline
\end{tabular}

n/a: not applicable. * Glycolysis type was defined as those positive for two or more of the glycolysis related proteins.

therapy; however, this remains to be verified in future studies that include clinical trials.

There are several limitations in this study. First, we used immunohistochemistry to evaluate glycolysis-related protein expression in FN and HCN, which has a limitation in quantification and with a possibility of interobserver bias. In addition, the results of immunohistochemical staining could be different depending on antibody reactivity. Second, as we used TMA, not whole section of the tumor specimen to evaluate the histological examination, there could be an extraction bias in TMA construction. However, as TMA has shown to be a reliable method for immunohistochemical analysis in clinicopathological characterization in various tissues including thyroid gland, using TMA to evaluate glycolysis-related protein expression might also be applicable. Third, although glycolysis-related protein expression was higher in HCNs and carcinomas compared to FNs and adenomas, the prognostic implication regarding disease-free and overall survival was not significant. Further investigation is required to elucidate the role of glycolysisrelated protein expression in predicting patient prognosis.

\section{Conclusion}

The expression levels of the glycolysis-related proteins Glut-1, hexokinase II, CAIX, and MCT4 are higher in HCNs compared to FNs and higher in HCCs than in HCAs. Moreover, our results showed that overexpression of each of these markers is associated with more aggressive tumor characteristics, thus providing potential therapeutic targets for HCN and FC.

\section{Conflicts of Interest}

The authors declare that there is no conflict of interest regarding the publication of this paper. 


\section{Acknowledgments}

This study was supported by a grant from the National R\&D Program for Cancer Control, Ministry of Health \& Welfare, Republic of Korea (1420080). This research was supported by the Basic Science Research Program through the National Research Foundation of Korea (NRF) funded by the Ministry of Science, ICT and Future Planning (2015R1A1A1A05001209).

\section{References}

[1] O. Warburg, "On the origin of cancer cells," Science, vol. 123, no. 3191, pp. 309-314, 1956.

[2] A. L. Olson and J. E. Pessin, "Structure, function, and regulation of the mammalian facilitative glucose transporter gene family," Annual Review of Nutrition, vol. 16, pp. 235-256, 1996.

[3] M. Lehto, K. Xiang, M. Stoffel et al., "Human hexokinase II: localization of the polymorphic gene to chromosome 2," Diabetologia, vol. 36, no. 12, pp. 1299-1302, 1993.

[4] R. Opavsky, S. Pastorekova, V. Zelnik et al., "Human MN/CA9 gene, a novel member of the carbonic anhydrase family: structure and exon to protein domain relationships," Genomics, vol. 33, no. 3, pp. 480-487, 1996.

[5] A. P. Halestrap and N. T. Price, "The proton-linked monocarboxylate transporter (MCT) family: structure, function and regulation," The Biochemical Journal, vol. 343, Part 2, pp. 281-299, 1999.

[6] c. Centre international de recherche sur le, R. A. DeLellis, and p. International academy of, Pathology and Genetics of Tumours of Endocrine Organs, IARC Press, Lyon, 2004.

[7] Y. E. Nikiforov, Diagnostic Pathology and Molecular Genetics of the Thyroid [a Comprehensive Guide for Practicing Thyroid Pathology; Includes Online Access to Fully Searchable Text and Image Bank!], u.a., Wolters Kluwer/Lippincott Williams \& Wilkins Health, Philadelphia, 2012.

[8] E. S. Cibas and S. Z. Ali, "The Bethesda system for reporting thyroid cytopathology," Thyroid, vol. 19, no. 11, pp. 11591165, 2009.

[9] C. S. Grant, D. Barr, J. R. Goellner, and I. D. Hay, "Benign Hurthle cell tumors of the thyroid: a diagnosis to be trusted?" World Journal of Surgery, vol. 12, no. 4, pp. 488-495, 1988.

[10] N. W. Thompson, E. L. Dunn, J. G. Batsakis, and R. H. Nishiyama, "Hurthle cell lesions of the thyroid gland," Surgery, Gynecology \& Obstetrics, vol. 139, no. 4, pp. 555-560, 1974.

[11] M. K. McLeod, N. W. Thompson, J. L. Hudson et al., "Flow cytometric measurements of nuclear DNA and ploidy analysis in Hurthle cell neoplasms of the thyroid," Archives of Surgery, vol. 123, no. 7, pp. 849-854, 1988.

[12] E. D. Rossi, M. Martini, P. Straccia et al., "The cytologic category of oncocytic (Hurthle) cell neoplasm mostly includes low-risk lesions at histology: an institutional experience," European Journal of Endocrinology, vol. 169, no. 5, pp. 649655, 2013.

[13] J. A. Bishop, G. Wu, R. P. Tufano, and W. H. Westra, "Histological patterns of locoregional recurrence in Hurthle cell carcinoma of the thyroid gland," Thyroid, vol. 22, no. 7, pp. 690-694, 2012.

[14] A. R. Shaha, J. P. Shah, and T. R. Loree, "Patterns of nodal and distant metastasis based on histologic varieties in differentiated carcinoma of the thyroid," American Journal of Surgery, vol. 172, no. 6, pp. 692-694, 1996.

[15] American Thyroid Association (ATA) Guidelines Taskforce on Thyroid Nodules and Differentiated Thyroid Cancer, D. S. Cooper, G. M. Doherty et al., "Revised American Thyroid Association management guidelines for patients with thyroid nodules and differentiated thyroid cancer," Thyroid, vol. 19, no. 11, pp. 1167-1214, 2009.

[16] S. C. Mills, M. Haq, W. J. Smellie, and C. Harmer, "Hurthle cell carcinoma of the thyroid: retrospective review of 62 patients treated at the Royal Marsden Hospital between 1946 and 2003," European Journal of Surgical Oncology, vol. 35, no. 3, pp. 230-234, 2009.

[17] Y. Kushchayeva, Q. Y. Duh, E. Kebebew, A. D'Avanzo, and O. H. Clark, "Comparison of clinical characteristics at diagnosis and during follow-up in 118 patients with Hurthle cell or follicular thyroid cancer," American Journal of Surgery, vol. 195, no. 4, pp. 457-462, 2008.

[18] I. Ganly, J. Ricarte Filho, S. Eng et al., "Genomic dissection of Hurthle cell carcinoma reveals a unique class of thyroid malignancy," The Journal of Clinical Endocrinology and Metabolism, vol. 98, no. 5, pp. E962-E972, 2013.

[19] A. M. Chindris, J. D. Casler, V. J. Bernet et al., "Clinical and molecular features of Hurthle cell carcinoma of the thyroid," The Journal of Clinical Endocrinology and Metabolism, vol. 100, no. 1, pp. 55-62, 2015.

[20] K. A. Pathak, T. Klonisch, R. W. Nason, and W. D. Leslie, "FDG-PET characteristics of Hurthle cell and follicular adenomas," Annals of Nuclear Medicine, vol. 30, no. 7, pp. 506-509, 2016.

[21] J. H. Nahm, H. M. Kim, and J. S. Koo, "Glycolysis-related protein expression in thyroid cancer," Tumour Biology, vol. 39, no. 3, article 1010428317695922, 2017.

[22] L. R. Henry, H. O. Lee, J. S. Lee et al., "Clinical implications of fibroblast activation protein in patients with colon cancer," Clinical Cancer Research, vol. 13, no. 6, pp. 1736-1741, 2007.

[23] K. Kakudo, T. Wakasa, Y. Ohta, K. Yane, Y. Ito, and H. Yamashita, "Prognostic classification of thyroid follicular cell tumors using Ki-67 labeling index: risk stratification of thyroid follicular cell carcinomas," Endocrine Journal, vol. 62, no. 1, pp. 1-12, 2015.

[24] Y. Ito, M. Hirokawa, A. Miyauchi et al., "Prognostic impact of Ki-67 labeling index in minimally invasive follicular thyroid carcinoma," Endocrine Journal, vol. 63, no. 10, pp. 913-917, 2016.

[25] F. Bertagna, G. Treglia, A. Piccardo et al., "F18-FDG-PET/CT thyroid incidentalomas: a wide retrospective analysis in three Italian centres on the significance of focal uptake and SUV value," Endocrine, vol. 43, no. 3, pp. 678-685, 2013.

[26] N. Samih, S. Hovsepian, A. Aouani, D. Lombardo, and G. Fayet, "Glut-1 translocation in FRTL-5 thyroid cells: role of phosphatidylinositol 3-kinase and N-glycosylation," Endocrinology, vol. 141, no. 11, pp. 4146-4155, 2000.

[27] L. G. Melstrom, M. R. Salabat, X. Z. Ding et al., "Apigenin inhibits the GLUT-1 glucose transporter and the phosphoinositide 3-kinase/Akt pathway in human pancreatic cancer cells," Pancreas, vol. 37, no. 4, pp. 426-431, 2008.

[28] K. J. Ahn, H. S. Hwang, J. H. Park et al., "Evaluation of the role of hexokinase type II in cellular proliferation and apoptosis using human hepatocellular carcinoma cell lines," Journal of Nuclear Medicine, vol. 50, no. 9, pp. 1525-1532, 2009. 
[29] S. Y. Lee, H. M. Jeon, M. K. Ju et al., "Wnt/Snail signaling regulates cytochrome C oxidase and glucose metabolism," Cancer Research, vol. 72, no. 14, pp. 3607-3617, 2012.

[30] Y. Sugishita, M. Kammori, O. Yamada et al., "Biological differential diagnosis of follicular thyroid tumor and Hurthle cell tumor on the basis of telomere length and hTERT expression," Annals of Surgical Oncology, vol. 21, no. 7, pp. 2318-2325, 2014.

[31] S. Bagheri, M. Nosrati, S. Li et al., "Genes and pathways downstream of telomerase in melanoma metastasis," Proceedings of the National Academy of Sciences of the United States of America, vol. 103, no. 30, pp. 11306-11311, 2006.

[32] K. C. Low and V. Tergaonkar, "Telomerase: central regulator of all of the hallmarks of cancer," Trends in Biochemical Sciences, vol. 38, no. 9, pp. 426-434, 2013.

[33] C. Capparelli, C. Guido, D. Whitaker-Menezes et al., "Autophagy and senescence in cancer-associated fibroblasts metabolically supports tumor growth and metastasis via glycolysis and ketone production," Cell Cycle, vol. 11, no. 12, pp. 22852302, 2012.

[34] S. Kamarajugadda, L. Stemboroski, Q. Cai et al., "Glucose oxidation modulates anoikis and tumor metastasis," Molecular and Cellular Biology, vol. 32, no. 10, pp. 1893-1907, 2012.

[35] H. M. Li, J. G. Yang, Z. J. Liu et al., "Blockage of glycolysis by targeting PFKFB3 suppresses tumor growth and metastasis in head and neck squamous cell carcinoma," Journal of Experimental \& Clinical Cancer Research, vol. 36, no. 1, p. 7, 2017.

[36] J. E. Kwon, W. H. Jung, and J. S. Koo, "Expression of glycolysis-related proteins in solid papillary carcinoma of the breast according to basement membrane status," Yonsei Medical Journal, vol. 55, no. 3, pp. 576-583, 2014.

[37] P. Swietach, R. D. Vaughan-Jones, and A. L. Harris, "Regulation of tumor $\mathrm{pH}$ and the role of carbonic anhydrase 9," Cancer Metastasis Reviews, vol. 26, no. 2, pp. 299-310, 2007.

[38] D. Whitaker-Menezes, U. E. Martinez-Outschoorn, Z. Lin et al., "Evidence for a stromal-epithelial "lactate shuttle" in human tumors: MCT4 is a marker of oxidative stress in cancer-associated fibroblasts," Cell Cycle, vol. 10, no. 11, pp. 1772-1783, 2011.

[39] M. Katagiri, H. Karasawa, K. Takagi et al., "Hexokinase 2 in colorectal cancer: a potent prognostic factor associated with glycolysis, proliferation and migration," Histology and Histopathology, vol. 32, no. 4, pp. 351-360, 2017.

[40] A. Wolf, S. Agnihotri, J. Micallef et al., "Hexokinase 2 is a key mediator of aerobic glycolysis and promotes tumor growth in human glioblastoma multiforme," The Journal of Experimental Medicine, vol. 208, no. 2, pp. 313-326, 2011.

[41] J. Chen, S. Zhang, Y. Li, Z. Tang, and W. Kong, "Hexokinase 2 overexpression promotes the proliferation and survival of laryngeal squamous cell carcinoma," Tumour Biology, vol. 35, no. 4, pp. 3743-3753, 2014.

[42] J. G. Pastorino and J. B. Hoek, "Hexokinase II: the integration of energy metabolism and control of apoptosis," Current Medicinal Chemistry, vol. 10, no. 16, pp. 1535-1551, 2003.

[43] Q. P. Peng, J. M. Zhou, Q. Zhou, F. Pan, D. P. Zhong, and H. J. Liang, "Downregulation of the hexokinase II gene sensitizes human colon cancer cells to 5-fluorouracil," Chemotherapy, vol. 54, no. 5, pp. 357-363, 2008.

[44] P. Goffredo, S. A. Roman, and J. A. Sosa, "Hurthle cell carcinoma: a population-level analysis of 3311 patients," Cancer, vol. 119, no. 3, pp. 504-511, 2013.
[45] M. A. Guerrero, I. Suh, M. R. Vriens et al., "Age and tumor size predicts lymph node involvement in Hurthle cell carcinoma," Journal of Cancer, vol. 1, pp. 23-26, 2010.

[46] A. Stojadinovic, A. Hoos, R. A. Ghossein et al., "Hurthle cell carcinoma: a 60-year experience," Annals of Surgical Oncology, vol. 9, no. 2, pp. 197-203, 2002.

[47] S. Ahmadi, M. Stang, X. S. Jiang, and J. A. Sosa, "Hurthle cell carcinoma: current perspectives," OncoTargets and Therapy, vol. 9, pp. 6873-6884, 2016.

[48] Y. Y. Bao, S. H. Zhou, J. Fan, and Q. Y. Wang, “Anticancer mechanism of apigenin and the implications of GLUT-1 expression in head and neck cancers," Future Oncology, vol. 9, no. 9, pp. 1353-1364, 2013.

[49] S. H. Zhou, J. Fan, X. M. Chen, K. J. Cheng, and S. Q. Wang, "Inhibition of cell proliferation and glucose uptake in human laryngeal carcinoma cells by antisense oligonucleotides against glucose transporter-1," Head \& Neck, vol. 31, no. 12, pp. 16241633, 2009.

[50] X. M. Luo, S. H. Zhou, and J. Fan, "Glucose transporter-1 as a new therapeutic target in laryngeal carcinoma," The Journal of International Medical Research, vol. 38, no. 6, pp. 1885-1892, 2010.

[51] U. Thamrongwaranggoon, W. Seubwai, C. Phoomak et al., "Targeting hexokinase II as a possible therapy for cholangiocarcinoma," Biochemical and Biophysical Research Communications, vol. 484, no. 2, pp. 409-415, 2017.

[52] A. Vartanian, S. Agnihotri, M. R. Wilson et al., "Targeting hexokinase 2 enhances response to radio-chemotherapy in glioblastoma," Oncotarget, vol. 7, no. 43, pp. 69518-69535, 2016.

[53] J. K. Ahlskog, C. E. Dumelin, S. Trussel, J. Marlind, and D. Neri, "In vivo targeting of tumor-associated carbonic anhydrases using acetazolamide derivatives," Bioorganic \& Medicinal Chemistry Letters, vol. 19, no. 16, pp. 48514856, 2009.

[54] F. E. Lock, P. C. McDonald, Y. Lou et al., "Targeting carbonic anhydrase IX depletes breast cancer stem cells within the hypoxic niche," Oncogene, vol. 32, no. 44, pp. 5210-5219, 2013.

[55] S. Y. Choi, H. Xue, R. Wu et al., "The MCT4 gene: a novel, potential target for therapy of advanced prostate cancer," Clinical Cancer Research, vol. 22, no. 11, pp. 2721-2733, 2016. 


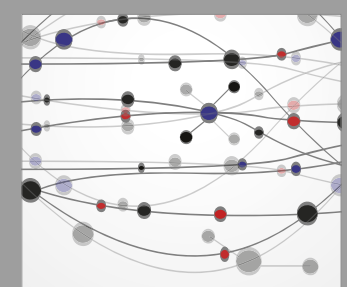

The Scientific World Journal
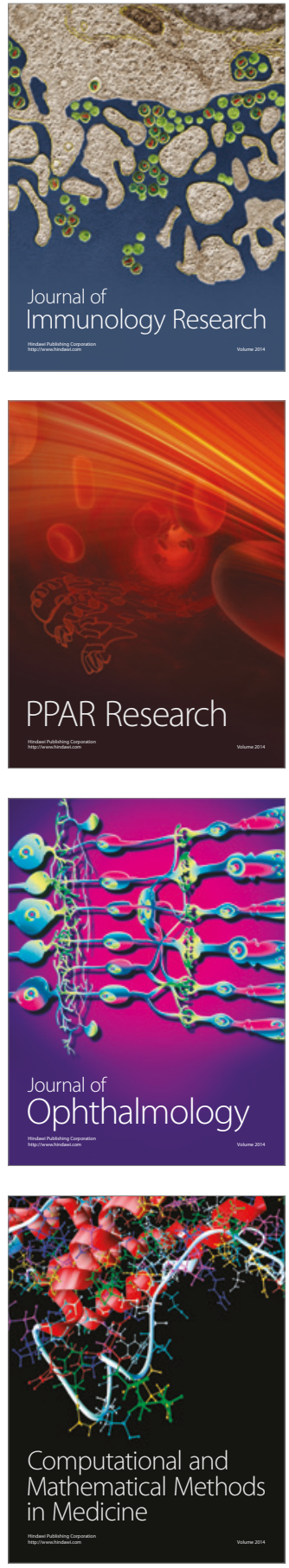

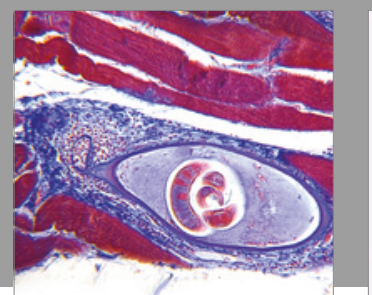

Gastroenterology Research and Practice
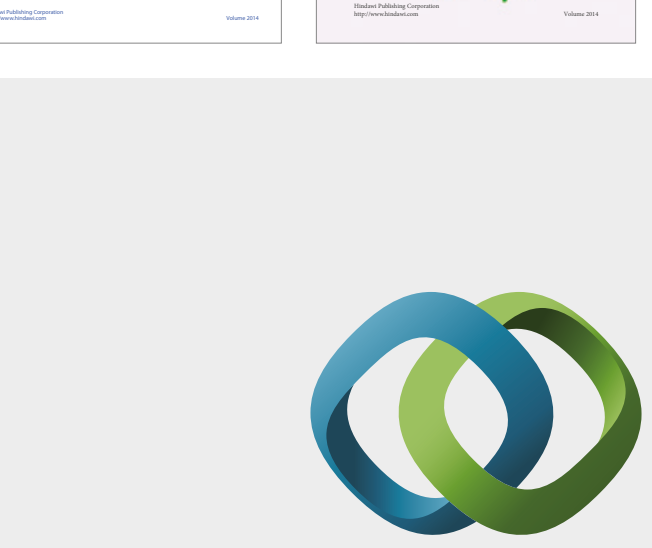

\section{Hindawi}

Submit your manuscripts at

https://www.hindawi.com
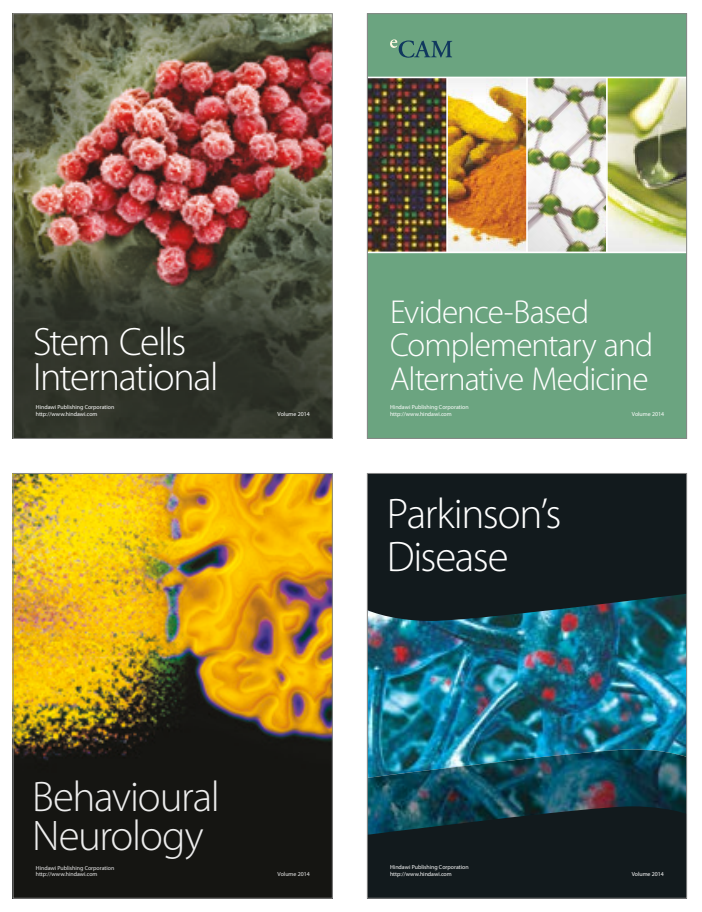
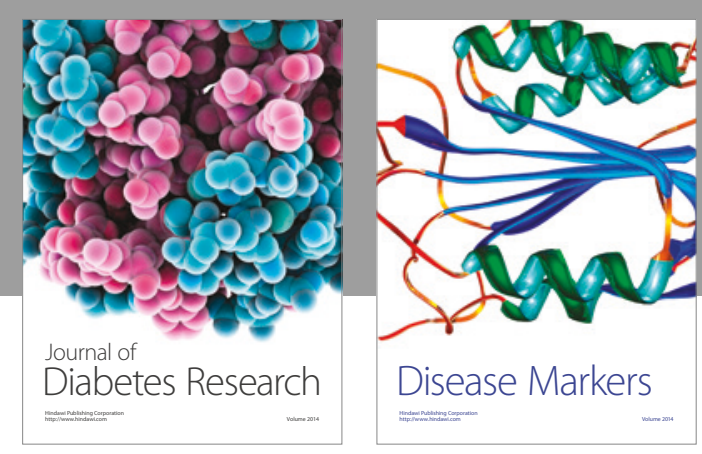

Disease Markers
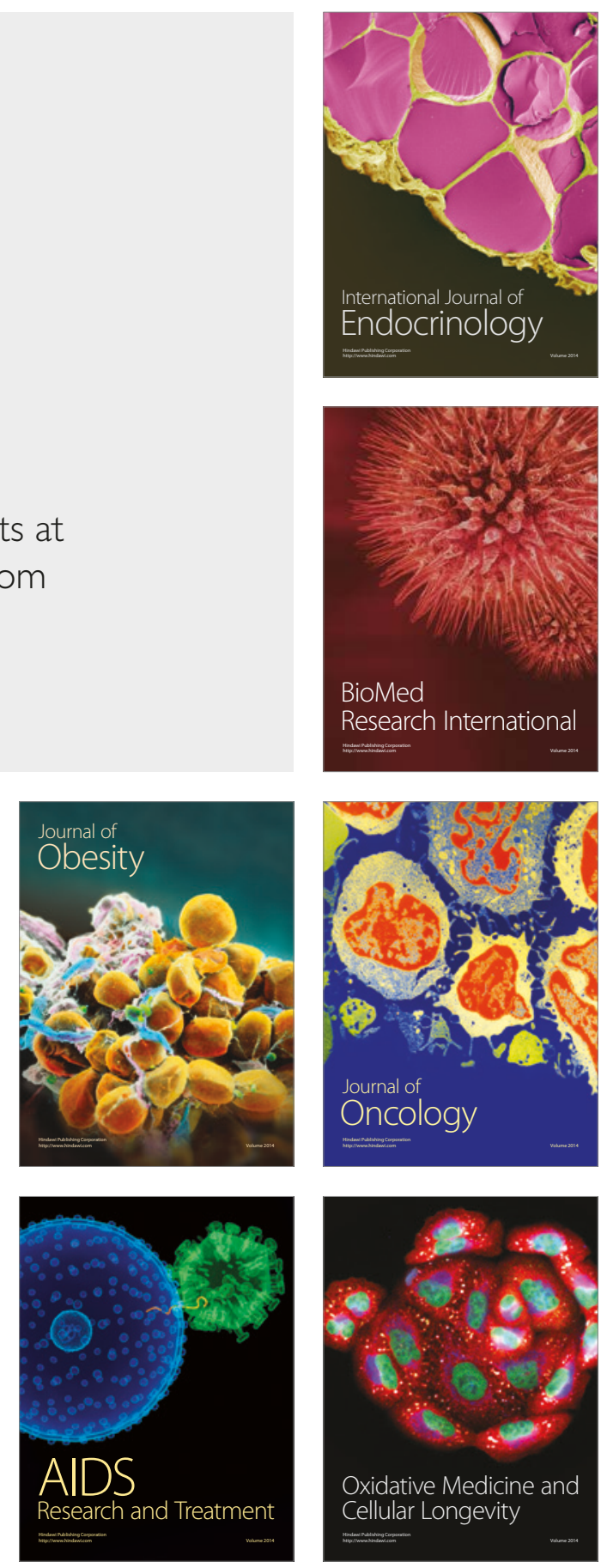